\title{
Sistemática filogenética de las lagartijas del género Stenocercus (Squamata: Iguania) de los Andes del norte
}

\author{
Phylogenetic systematics of lizards of the genus Stenocercus (Squamata: Iguania) from the \\ northern Andes
}

\author{
Omar Torres-Carvajal \\ Department of Vertebrate Zoology, National Museum of Natural History, Smithsonian Institution. Washington DC 20560, USA. \\ Dirección actual: Escuela de Biología, Pontificia Universidad Católica del Ecuador. Avenida 12 de octubre y Roca, Apartado 17-01-2184, Quito, \\ Ecuador. \\ Correspondencia: omartorcar@gmail.com
}

\begin{abstract}
Resumen. El género Stenocercus está compuesto por 61 especies que se distribuyen principalmente en los Andes y tierras bajas aledañas (0-4 $000 \mathrm{~m}$ ), desde el norte de Colombia y Venezuela hasta el centro de Argentina. En este trabajo se realizaron análisis de parsimonia e inferencia bayesiana para estudiar las relaciones filogenéticas entre las 20 especies de Stenocercus que habitan en los Andes del norte (Ecuador, Colombia y Venezuela), utilizando datos morfológicos y moleculares por separado y en combinación. Los análisis dieron como resultado topologías similares indicando que las especies de Stenocercus de los Andes del norte están divididas en 2 clados. Uno contiene 6 especies distribuidas entre el sur de Ecuador y sur de Colombia, mientras que el otro tiene 13 especies distribuidas desde el sur de Ecuador hasta el norte de Colombia y Venezuela. Los resultados también sugieren que la reciente formación de los Andes del norte ha tenido gran influencia sobre la evolución de Stenocercus.
\end{abstract}

Palabras clave: ADN mitocondrial, biogeografía, caracteres continuos, caracteres polimórficos, inferencia bayesiana, morfología, parsimonia.

\begin{abstract}
The genus Stenocercus is composed of 61 species that occur mainly in the Andes and adjacent lowland areas (0-4 $000 \mathrm{~m})$ from northern Colombia and Venezuela to central Argentina. In this study, I performed parsimony and Bayesian analyses to infer the phylogenetic relationships among the 20 species of Stenocercus that occur in the northern Andes (Ecuador, Colombia, and Venezuela); I analyzed morphological, molecular, and combined datasets. These analyses resulted in similar topologies, which indicate that species of Stenocercus from the northern Andes are nested within 2 major clades. One of these clades contains 6 species occurring between southern Ecuador and southern Colombia, whereas the other clade includes 13 species that occur from southern Ecuador to northern Colombia and Venezuela. The results also suggest that the recent uplift of the northern Andes has had a major impact on the evolution of Stenocercus.
\end{abstract}

Key words: Bayesian inference, biogeography, continuous characters, mitochondrial DNA, morphology, parsimony, polymorphic characters.

\section{Introducción}

Las lagartijas del género Stenocercus (familia Tropiduridae según Frost et al., 2001a; Iguanidae según Macey et al., 1997; subfamilia Tropidurinae, tribu Tropidurini según Schulte et al., 2003) representan uno de los grupos de reptiles de más amplia distribución geográfica y ecológica en Sudamérica. Actualmente, este género está compuesto por 61 especies que se distribuyen principalmente sobre la cordillera de los Andes y tierras bajas aledañas (0-4000 m), desde el norte de Venezuela y Colombia hasta el centro de Argentina (Torres-Carvajal,

Recibido: 01 noviembre 2007; aceptado: 15 enero 2009 2007a). Estas lagartijas ocupan una gran variedad de hábitats, tales como bosques secos, bosques húmedos, puna y páramo.

Hasta hace poco, las descripciones de especies nuevas y revisiones taxonómicas constituían la mayoría de estudios relacionados con sistemática de Stenocercus, incluyendo una cantidad considerable de especies nuevas que se han descrito recientemente. Tal es así, que a partir de 1980 se ha descrito aproximadamente un tercio de las especies de Stenocercus (Ayala y Castro, 1982; Corredor, 1983; Cadle, 1991, 1998, 2001; Ávila-Pires, 1995; TorresCarvajal, 2000, 2005a, 2005b, 2005c, 2007b). Una de las principales causas para este reciente descubrimiento de tantas especies nuevas es la recolección de ejemplares en 
áreas anteriormente poco exploradas en los Andes (e.g., Lehr, 2002). Otra causa es que no todas las colecciones existentes han sido examinadas en detalle y contienen especies no descritas que han permanecido erróneamente identificadas (e.g., Cadle, 2001; Torres-Carvajal, 2005a, 2005b, 2005c). Además de las descripciones de especies nuevas, se han publicado revisiones taxonómicas de aquellas especies que habitan en Ecuador (Torres-Carvajal, 2000), norte del Perú (Cadle, 1991, 1998) y Amazonia de Brasil (Ávila-Pires, 1995), así como una revisión completa del género (Torres-Carvajal, 2007a).

Hasta el año 2006, la gran cantidad de estudios taxonómicos de Stenocercus contrastaban con el escaso número de estudios filogenéticos, que además incluían apenas entre 1 y 4 especies de este género (e.g., Frost, 1992; Schulte et al., 1998, 2003; Harvey y Gutberlet, 2000; Frost et al., 2001b). Hace más de 3 décadas, Fritts (1974) presentó el primer análisis filogenético de Stenocercus basado en el algoritmo filético cuantitativo propuesto por Kluge y Farris (1969). En este estudio, Fritts (1974) incluyó 19 especies de Stenocercus y 29 caracteres morfológicos. Basándose en el árbol resultante de Wagner, Fritts (1974) concluyó que Stenocercus estaba compuesto por 3 clados principales. Etheridge y de Queiroz (1988) propusieron que los géneros Stenocercus, Ophryoessoides y Proctotretus formaban un grupo monofilético, al cual denominaron Grupo Stenocercus e identificaron como taxón hermano del Grupo Tropidurus. Esta misma relación de taxones hermanos ha sido propuesta repetidas veces en estudios posteriores (e.g., Frost y Etheridge, 1989; Frost, 1992; Frost et al., 2001b; Schulte et al., 2003). Sin embargo, Etheridge y de Queiroz (1988) reconocieron que la monofilia de Stenocercus carecía de buen soporte, ya que se justificaba únicamente por la presencia de un "dentario largo". Estos mismos autores mencionaron además la posibilidad de que Stenocercus sea parafilético, ya que no encontraron ningún carácter o combinación de caracteres para diagnosticar este género en relación a Ophryoessoides y Proctotretus. Un año más tarde, Frost y Etheridge (1989) concluyeron que el Grupo Stenocercus estaba pobremente definido por un agrandamiento secundario del angular y por la gran extensión del músculo transversus penis a lo largo del tabique traslúcido de la vaina hemipenial. En su estudio sobre la filogenia del Grupo Tropidurus, Frost (1992) propuso reconocer las tribus Tropidurini (Grupo Tropidurus) y Stenocercini (Grupo Stenocercus) dentro de la subfamilia Tropidurinae, familia Tropiduridae. Además, Frost (1992) sinonimizó Ophryoessoides y Proctotretus con Stenocercus, con base en evidencia morfológica que sugiere que Ophryoessoides y Proctotretus se derivaron de Stenocercus. Recientemente se publicaron 2 estudios filogenéticos de Stenocercus basados en caracteres moleculares y morfológicos (Torres-Carvajal et al., 2006; Torres-Carvajal, 2007c); estos estudios concluyen o corroboran que 1) Stenocercus es monofilético; 2) el grupo hermano de Stenocercus es el Grupo Tropidurus; 3) Ophryoessoides no es monofilético; 4) las especies de Stenocercus están divididas en 2 clados principales, y 5) el ancestro común de Stenocercus posiblemente habitaba en la cordillera oriental de los Andes centrales.

De las 61 especies de Stenocercus reconocidas actualmente, 20 habitan en los Andes del norte (Fig. 1, Cuadro 1), con 15 especies en Ecuador (10 endémicas; Torres-Carvajal 2000, 2005a), 7 en Colombia (4 endémicas), y 1 en Venezuela (no endémica). En este estudio se utilizaron caracteres morfológicos y moleculares para inferir las relaciones filogenéticas entre las especies de Stenocercus que habitan en los Andes del norte.

\section{Materiales y métodos}

Para obtener los datos morfológicos se examinaron 900 ejemplares de 19 especies de Stenocercus de los Andes del norte y 4 de Microlophus occipitalis, el cual fue utilizado como grupo externo en los análisis filogenéticos (Apéndice 1). Para los datos moleculares se obtuvieron secuencias del ADN mitocondrial de Microlophus atacamensis (grupo externo) y 11 de las 20 especies de Stenocercus de los Andes del norte (Cuadro 2).

Se examinaron 123 caracteres morfológicos -91 discretos y no variables, 15 polimórficos y 17 merísticos-, que describe Torres-Carvajal (2005d, 2007c). Los caracteres polimórficos se refieren a aquellos caracteres discretos que varían intraespecíficamente. Se analizaron 2 sets de datos morfológicos bajo el criterio de parsimonia: En el primer set se incluyeron únicamente los 91 caracteres discretos no variables; en el segundo, todos los 123 caracteres. El primer set de datos fue analizado con una búsqueda branch and bound. Para el segundo, se realizó una búsqueda heurística con 10.000 réplicas aleatorias de secuencia aditiva (random addition sequence replicates), utilizando la permutación de ramas tipo TBR (tree bisection and reconnection). El soporte para cada nodo se evaluó con la técnica de bootstrap no paramétrico (BP; Felsenstein, 1985), con 100 réplicas de bootstrap, y 1000 (set 1) y 100 (set 2) réplicas aleatorias de secuencia aditiva.

Los caracteres polimórficos se analizaron con el método MANOB de parsimonia para frecuencias (frequency parsimony; Swofford y Berlocher, 1987) con matrices de pasos (Wiens, 1995). Según este método, el criterio para elegir el mejor árbol se basa en la longitud, de acuerdo con distancias de Manhattan, con la limitación de que a 


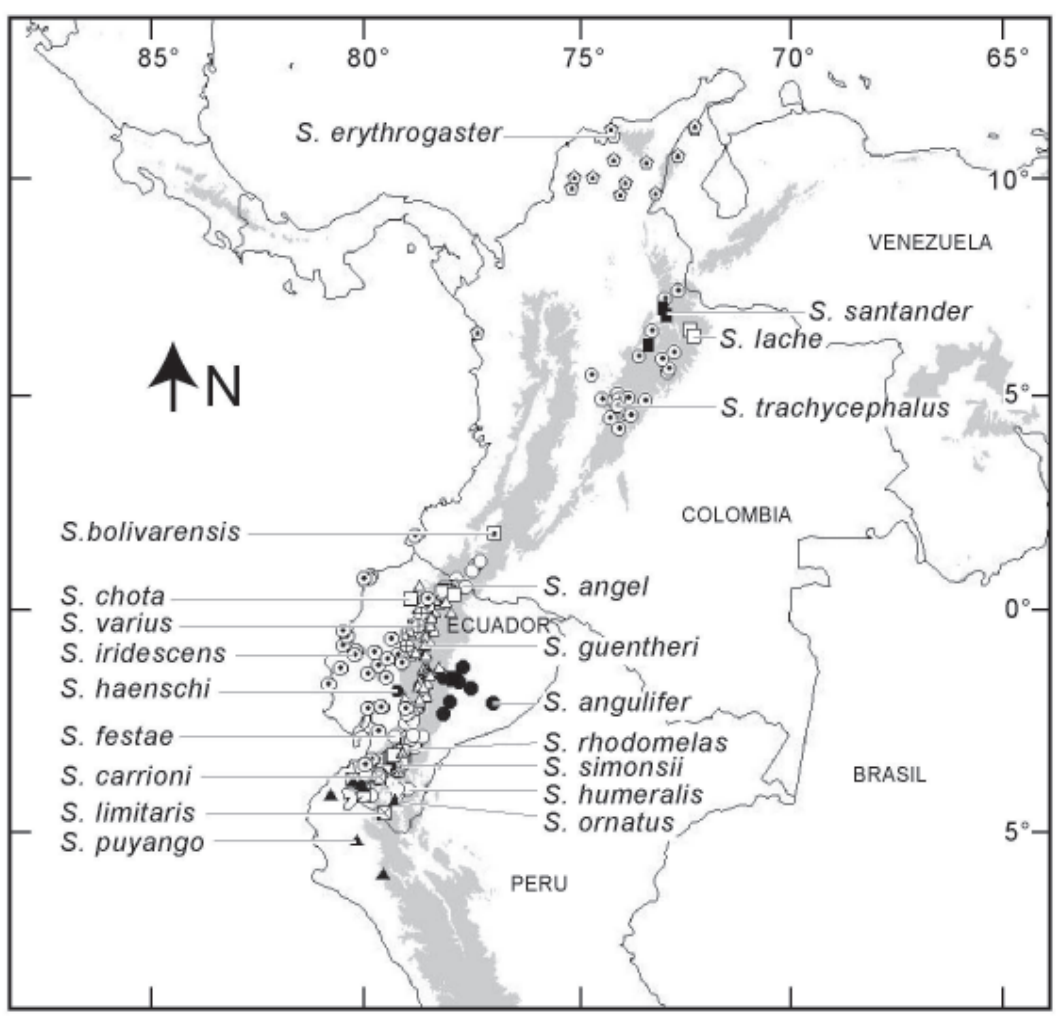

Figura 1. Distribución de Stenocercus en los Andes del norte. En gris, se indican las áreas a más de 1500 m de elevación. los ancestros hipotéticos se les puede asignar únicamente las frecuencias de estados de caracteres observadas (Swofford y Berlocher, 1987). Pese a que el método MANOB de parsimonia para frecuencias originalmente fue propuesto para analizar datos de las de genes (Swofford y Berlocher, 1987), también puede ser aplicado a caracteres morfológicos polimórficos (Wiens, 1995, 2000). En este método se asigna un estado de carácter diferente para cada taxón. Para un carácter dado, primero se calcula el costo de transición entre los diferentes estados con base en las distancias de Manhattan entre cada par de especies, las cuales a su vez se calculan a partir de las frecuencias observadas. Luego se especifican todos los costos calculados en una matriz de pasos. La distancia de Manhattan $D$ entre 2 taxa $(A$ y $B$ ) se calcula con la siguiente fórmula:

$$
D(A, B)=1 / 2 \sum_{j=1}^{N}\left|x_{A j}-x_{B j}\right|
$$

Cuadro 1. Distribución de las especies de Stenocercus de los Andes del norte

\begin{tabular}{|c|c|c|c|c|}
\hline \multirow[t]{2}{*}{ Especie } & \multirow[t]{2}{*}{ País } & \multicolumn{2}{|c|}{ Rango latitudinal } & \multirow[t]{2}{*}{ Altitud (m) } \\
\hline & & $S$ & $N$ & \\
\hline S. angulifer & Ecuador, Perú & $8^{\circ} \mathrm{S}$ & $1^{\circ} \mathrm{S}$ & $537-1311$ \\
\hline S. angel & Colombia, Ecuador & $0^{\circ} 30^{\prime} \mathrm{N}$ & $1^{\circ} 30^{\prime} \mathrm{N}$ & $3015-3560$ \\
\hline S. bolivarensis & Colombia & $1^{\circ} \mathrm{N}$ & $2^{\circ} \mathrm{N}$ & $1650-1750$ \\
\hline S. carrioni & Ecuador & $4^{\circ} \mathrm{S}$ & $4^{\circ} \mathrm{S}$ & $1320-1900$ \\
\hline S. chota & Ecuador & $0^{\circ} 20^{\prime} \mathrm{N}$ & $0^{\circ} 40^{\prime} \mathrm{N}$ & $1575-1940$ \\
\hline S. erythrogaster & Colombia, Venezuela & $9^{\circ} \mathrm{N}$ & $11^{\circ} \mathrm{N}$ & $50-1000$ \\
\hline S. festae & Ecuador & $4^{\circ} \mathrm{S}$ & $2^{\circ} 20^{\prime} \mathrm{S}$ & $2300-3200$ \\
\hline S. guentheri & Ecuador & $2^{\circ} 20^{\prime} \mathrm{S}$ & $0^{\circ} 30^{\prime} \mathrm{N}$ & $2135-3890$ \\
\hline S. haenschi & Ecuador & $2^{\circ} \mathrm{S}$ & $1^{\circ} \mathrm{S}$ & 750 \\
\hline S. humeralis & Ecuador & $4^{\circ} \mathrm{S}$ & $3^{\circ} \mathrm{S}$ & $2000-3000$ \\
\hline S. iridescens & Colombia, Ecuador & $3^{\circ} 30^{\prime} \mathrm{S}$ & $2^{\circ} \mathrm{N}$ & $0-2000$ \\
\hline S. lache & Colombia & $6^{\circ} \mathrm{N}$ & $7^{\circ} \mathrm{N}$ & $2908-4000$ \\
\hline S. limitaris & Ecuador, Perú & $5^{\circ} \mathrm{S}$ & $3^{\circ} \mathrm{S}$ & $600-2200$ \\
\hline S. ornatus & Ecuador & $4^{\circ} 30^{\prime} \mathrm{S}$ & $4^{\circ} \mathrm{S}$ & $1500-3000$ \\
\hline S. puyango & Ecuador, Perú & $6^{\circ} \mathrm{S}$ & $3^{\circ} 30^{\prime} \mathrm{S}$ & $90-1500$ \\
\hline S. rhodomelas & Ecuador & $3^{\circ} 30^{\prime} \mathrm{S}$ & $3^{\circ} \mathrm{S}$ & $730-2100$ \\
\hline S. santander & Colombia & $6^{\circ} \mathrm{N}$ & $7^{\circ} \mathrm{N}$ & $1189-1570$ \\
\hline S. simonsii & Ecuador & $4^{\circ} \mathrm{S}$ & $3^{\circ} \mathrm{S}$ & $1980-2500$ \\
\hline S. trachycephalus & Colombia & $4^{\circ} \mathrm{N}$ & $6^{\circ} \mathrm{N}$ & $1749-3800$ \\
\hline S. varius & Ecuador & $1^{\circ} \mathrm{S}$ & $0^{\circ}$ & $1460-2200$ \\
\hline
\end{tabular}


Cuadro 2. Nombres, números de colección, localidades y números de acceso a GenBank de las especies utilizadas en los analisis moleculares. Todos los números GenBank fueron publicados por Torres-Carvajal et al. (2006) excepto Microlophus atacamensis (Schulte et al., 2003)

\begin{tabular}{|c|c|c|}
\hline Especie & Número de colección y localidad & Núm. GenBank \\
\hline Microlophus atacamensis & JPV 145; Chile: Atacama: Pan de Azucar (26 8' 60’' S, 70³9' 0’’ W) & AF528752 \\
\hline Stenocercus angel & $\begin{array}{l}\text { QCAZ 4118; Ecuador: Carchi: } 8 \mathrm{~km} \text { NE El Angel carretera El Angel-Tulcán, } 3560 \\
\mathrm{~m}\left(0^{\circ} 40^{\prime} 0^{\prime \prime} \mathrm{N}, 77^{\circ} 52^{\prime} 0^{\prime \prime} \mathrm{W}\right)\end{array}$ & DQ080212 \\
\hline S. chota & QCAZ 4162; Ecuador: Imbabura: Salinas, 1544 m (0'30' 0’' N, 78º 8' 0’' W) & DQ080217 \\
\hline S. festae & QCAZ 5599; Ecuador: Azuay: Sigsig, 2684 m (3 3' 0’’ S, 78 48' 0’' W) & DQ080221 \\
\hline S. guentheri & KU 218382; Ecuador: Pichincha: 20.9 km N Quito (00' 40’’ N, 78 29' 7’' W) & DQ080223 \\
\hline S. humeralis & $\begin{array}{c}\text { KU 291508; Ecuador: Loja: } 27 \text { km W Loja carretera Loja-Zamora, } 2078 \text { m (4 0' } \\
\left.\text { 0"' S, 78 } 78^{\circ} 58^{\prime} 25^{\prime \prime} \mathrm{W}\right)\end{array}$ & DQ080224 \\
\hline S. iridescens & QCAZ 6194; Ecuador: Esmeraldas: Tonchigüe, $10 \mathrm{~m}\left(0^{\circ} 49^{\prime} 0^{\prime \prime} \mathrm{N}, 79^{\circ} 57^{\prime} 0^{\prime \prime} \mathrm{W}\right)$ & DQ080226 \\
\hline S. limitaris & $\begin{array}{l}\text { MCZ 182245; Peru: Piura: Toronche (ca. } 16 \text { km airline SE Ayabaca), 1950-2100 } \\
\left.\text { m ( } 4^{\circ} 35^{\prime} 0^{\prime \prime} \mathrm{S}, 79^{\circ} 32^{\prime} 0^{\prime \prime} \mathrm{W}\right)\end{array}$ & DQ080228 \\
\hline S. ornatus & $\begin{array}{l}\text { KU 291509; Ecuador: Loja: Purunuma, faldas del Cerro Colambo (4 } 12^{\prime} 0^{\prime \prime} \mathrm{S} \text {, } \\
\left.\qquad 79^{\circ} 24^{\prime} 0^{\prime \prime} \mathrm{W}\right)\end{array}$ & DQ080231 \\
\hline S. puyango & 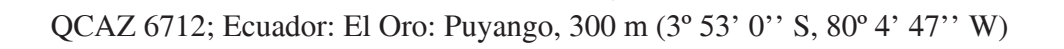 & DQ080233 \\
\hline S. rhodomelas & 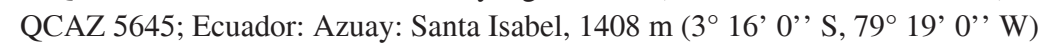 & DQ080234 \\
\hline S. varius & QCAZ 5312; Ecuador: Cotopaxi: Reserva La Otonga & DQ080237 \\
\hline
\end{tabular}

donde $N$ es el número total de estados de caracteres, mientras que $\mathrm{x}_{A}, \mathrm{x}_{B}$ son las frecuencias observadas para un estado de carácter dado $(j)$ en los taxa $A$ y $B$ respectivamente. Las matrices de pasos fueron calculadas con el programa PAUP* (Swofford, 2003) tras importar archivos en formato FREQPARS que contenían los datos de las frecuencias observadas.

Los caracteres merísticos se analizaron mediante el método de gap-weighting (Thiele, 1993) utilizando matrices de pasos, tal como lo propuso Wiens (2001), pero con ciertas modificaciones. Lo que Thiele (1993) propuso fue tomar en cuenta las diferencias entre los valores de los caracteres continuos observados, asignando pesos menores a diferencias pequeñas y pesos mayores a diferencias grandes. Para cada carácter continuo, este método consiste en 1) calcular la media aritmética (promedio) de dicho carácter para cada taxón, así como el rango de valores de los promedios en todos los taxa, y 2) dividir ese rango en un cierto número de rangos más pequeños equivalente al número máximo de estados de caracteres permitido por el programa (Thiele, 1993). Para superar esta limitación en el número máximo de rangos, Wiens (2001) propuso utilizar matrices de pasos para pesar las diferencias entre las medias de los caracteres continuos. Es decir, las matrices de pasos nos permiten analizar cuantos rangos sean necesarios, independientemente del número máximo de estados de caracteres permitido por cualquier programa. Así, a cada taxón con un valor de media aritmética único se le asigna un estado de carácter único. El cambio de un estado de carácter a otro tiene un costo que está especificado en la matriz de pasos; este costo se calcula de acuerdo a la diferencia observada al comparar las medias aritméticas entre cada par de taxa (Wiens, 2001). Ya que el costo máximo en una matriz de pasos en PAUP* es 1000, Wiens (2001) propuso modificar la fórmula propuesta por Thiele (1993) convirtiendo el valor de la media aritmética $(x)$ de cada taxón en un puntaje $\left(X_{s}\right)$ de $0-1000$ :

$$
X_{s}=\frac{x-\min }{\max -\min } \times 1000
$$

donde "min" y "max" son los valores mínimo y máximo de las medias aritméticas observadas en todo los taxa. La diferencia entre estos puntajes $\left(X_{s}\right)$ determina el costo de las transformaciones entre los estados de caracteres en la matriz de pasos. La fórmula presentada arriba implica que aquellos caracteres no continuos presentes en la matriz de datos deben ser pesados con un valor de 1000 . Para evitar este último paso, se modificó esta fórmula eliminando la multiplicación por 1000 . Esto implica que las matrices de pasos pueden tener solamente valores de $0-1$, lo cual evita el tener que pesar los caracteres no continuos con un valor de 1000 , ya que el peso preestablecido en PAUP* es 1. Las matrices de pasos fueron construidas de la siguiente manera: 1) se utilizaron los puntajes $\left(X_{s}\right)$ para crear un archivo con formato FREQPARS, y 2) se importó este archivo FREQPARS en el programa PAUP*, el cual 
calcula las matrices de pasos automáticamente cuando importa este tipo de archivos. El archivo FREQPARS se construyó creando estados de caracteres "falsos" $(Y)$ para cada puntaje $\left(X_{s}\right)$ :

$$
Y=1-X_{s}
$$

Las distancias de Manhattan calculadas con estos valores (i.e., puntajes y correspondientes estados de caracteres "falsos") son equivalentes a las diferencias entre los puntajes porque no existen más de 2 estados, y el segundo $(Y)$ siempre es redundante con respecto al primero $\left(X_{s}\right)$.

Los datos moleculares fueron analizados bajos los criterios de parsimonia e inferencia bayesiana. Se obtuvieron de GenBank secuencias del ADN mitocondrial de 11 especies de Stenocercus y Microlophus atacamensis, que fue utilizada como grupo externo (Cuadro 2). Los protocolos para la extracción, amplificación y secuenciación de estas muestras se describen en TorresCarvajal et al. (2006). Cada secuencia está compuesta por 1786 caracteres (incluyendo gaps) que se extienden desde el gen $N D 1$ hasta el gen $C O I$, incluyendo los genes que codifican para $\mathrm{ARNt}^{\mathrm{Hle}}, \mathrm{ARNt}^{\mathrm{Gln}}, \mathrm{ARNt}^{\mathrm{Met}}, \mathrm{ND} 2, \mathrm{ARNt}^{\mathrm{Trp}}$, $\mathrm{ARNt}^{\mathrm{Ala}}, \mathrm{ARNt}^{\mathrm{Asn}}$, origen de la hélice ligera (L), $\mathrm{ARNt}^{\mathrm{Cys}} \mathrm{y}$ $\mathrm{ARNt}^{\mathrm{Tyr}}$. Las secuencias fueron alineadas con la ayuda del programa ClustalX 1.83 (Thompson et al., 1997); también se realizaron ajustes manuales sobre aquellas secuencias que codifican para ARNt utilizando modelos estándar de ARNt (Kumazawa y Nishida, 1993; Macey y Verma, 1997). Aquellos genes que codifican proteínas (ND1, ND2, COI) fueron traducidos a aminoácidos utilizando MacClade 4.03 (Maddison y Maddison, 2001) para confirmar la alineación. Se excluyeron de los análisis 145 pares de bases de homología ambigua. Para el análisis de parsimonia se realizó una búsqueda heurística con 10.000 réplicas aleatorias de secuencia aditiva (random addition sequence replicates), utilizando la permutación de ramas tipo TBR (tree bisection and reconnection). El soporte para cada nodo se evaluó con la técnica de bootstrap no paramétrico con 1000 réplicas de bootstrap y 5 réplicas aleatorias de secuencia aditiva. Para la inferencia bayesiana, primeramente se determinó el mejor modelo de evolución según el criterio de información de Akaike (Akaike, 1973), con la ayuda del programa MrModeltest 2.2 (Nylander, 2005). Una vez seleccionado el modelo se realizaron 4 análisis en MrBayes 3.0b4 (Ronquist y Huelsenbeck, 2003), cada uno con 4 cadenas Markov y 2 millones de generaciones. Los valores de los parámetros para el modelo fueron estimados a partir de los datos, e iniciados con las probabilidades a priori predeterminadas en MrBayes. Los árboles fueron muestreados cada 100 generaciones, es decir se obtuvieron 20000 árboles en cada uno de los 4 análisis. Luego de verificar visualmente la convergencia en el programa Tracer 1.2 (Rambaut y Drummond, 2003), se descartaron (burn-in) 5000 generaciones por análisis. Los valores de probabilidades a posteriori fueron obtenidos a partir de 60000 árboles resultantes a través de un árbol de compromiso de $50 \%$ en PAUP*. El mismo protocolo fue utilizado para el análisis bayesiano de los datos moleculares y morfológicos en combinación.

\section{Resultados}

El análisis de parsimonia del primer set de datos morfológicos (i.e., 91 caracteres discretos no variables) dio como resultado 608 árboles igualmente parsimoniosos de 126 pasos cada uno, con un índice de consistencia de 0.67 y un índice de retención de 0.80. Este set de datos incluye 20 caracteres constantes y 48 parsimónicamente informativos. De acuerdo con la topología del árbol de consenso estricto resultante de este análisis (Fig. 2), las especies de Stenocercus de los Andes del norte se agrupan en 2 clados poco resueltos: uno con bajo soporte de bootstrap $(\mathrm{BP}=65)$ y 13 especies - $(S$. angel, S. chota, S. festae, S. guentheri, S. lache, S. trachycephalus ( $S$. iridescens, S. limitaris, S. puyango, (S. angulifer, S. erythrogaster)), (S. ornatus, $S$. rhodomelas) ) - y el otro con un buen soporte y 6 especies - $(S$. haenschi $(S$. bolivarensis, $S$. carrioni, $S$. humeralis, $S$. simonsii, $S$, varius) - Dentro del primer clado existe solamente un subclado con buen soporte $(\mathrm{BP}=96)$ que incluye 5 especies $(S$. angulifer, $S$. erythrogaster, $S$. iridescens, S. limitaris y $S$. puyango), las cuales presentan aquellos caracteres utilizados por Fritts (1974) para definir "Ophryoessoides". De manera similar, el segundo clado también contiene un subclado con buen soporte $(\mathrm{BP}=96)$ de cinco especies $(S$. bolivarensis, $S$. carrioni, $S$. humeralis, $S$. simonsii y $S$. varius).

El análisis de parsimonia del segundo set de datos morfológicos (i.e., 91 discretos no variables, 15 polimórficos y 17 merísticos) dio como resultado un árbol más parsimonioso de 176394 pasos, con un índice de consistencia de 0.60 y un índice de retención de 0.74 (Fig. 2). Este set de datos incluye 20 caracteres constantes y 75 parsimónicamente informativos. Pese a que el árbol resultante de este análisis tiene mayor resolución que el árbol de consenso estricto del análisis anterior, ambos árboles presentan la misma bifurcación basal que divide las especies de Stenocercus en 2 clados de 6 y 13 especies. Nuevamente, el clado de 6 especies - $(S$. haenschi ( $(S$. bolivarensis, S. carrioni), (S. varius (S. humeralis, $S$. simonsii)) ) ) - recibe el mayor soporte de bootstrap, mientras que el clado de 13 especies - (S. angel (S. chota (S. guentheri $(S$. lache (S. festae ( $(S$. trachycephalus $(S$. 
PARSIMONIA MORFOLOGIA (set 1)

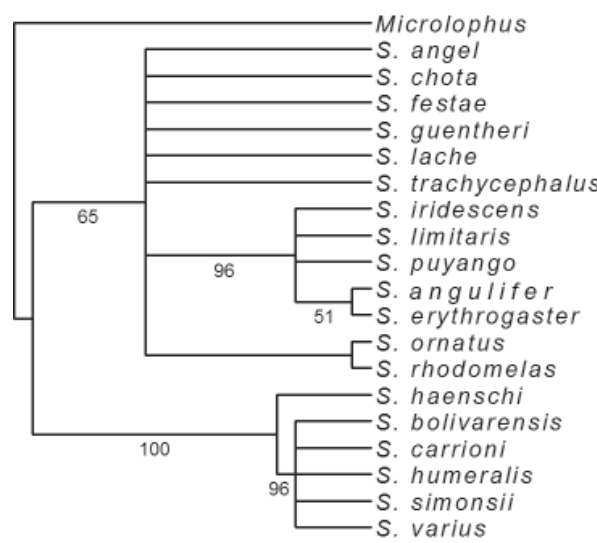

PARSIMONIA

\section{ADNmt}

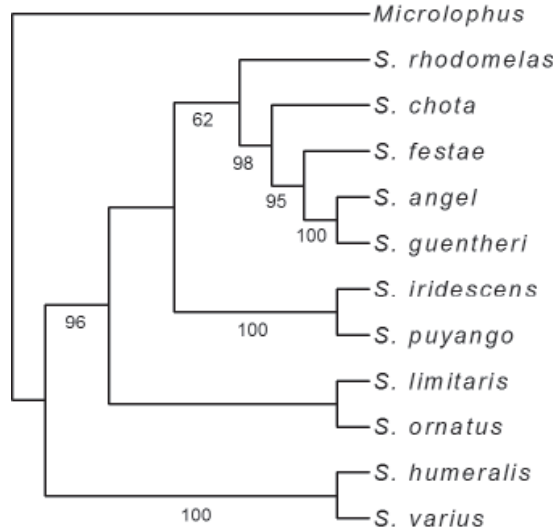

INFERENCIA BAYESIANA ADNmt

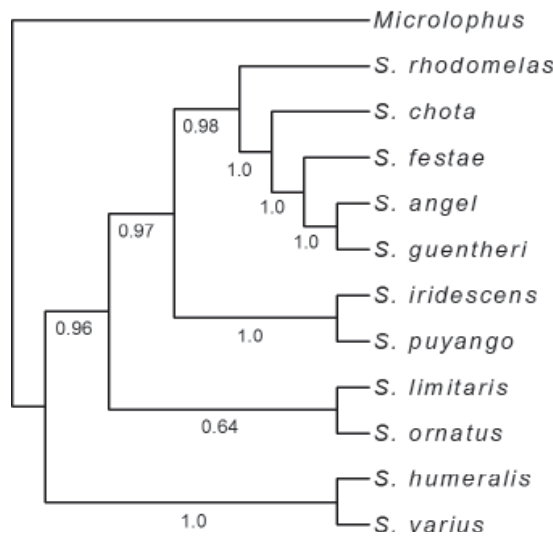

PARSIMONIA MORFOLOGIA (set 2)

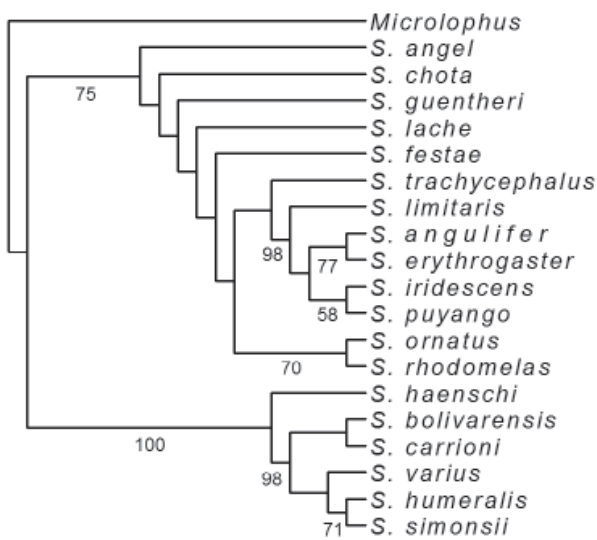

PARSIMONIA

ADNmt + MORFOLOGIA (set 2)

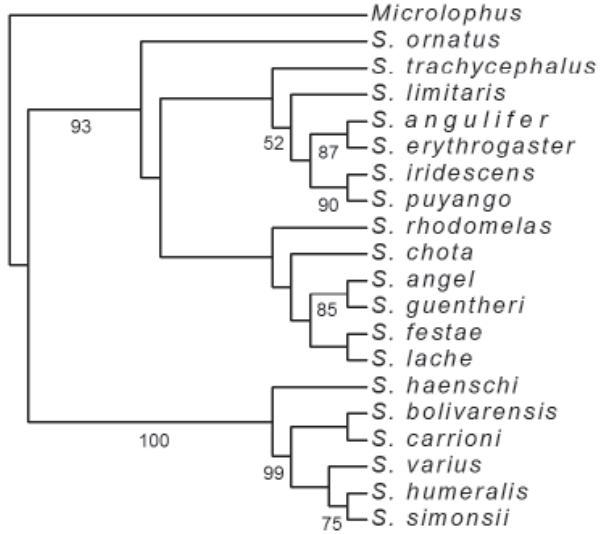

INFERENCIA BAYESIANA

ADNmt + MORFOLOGIA (set 2)

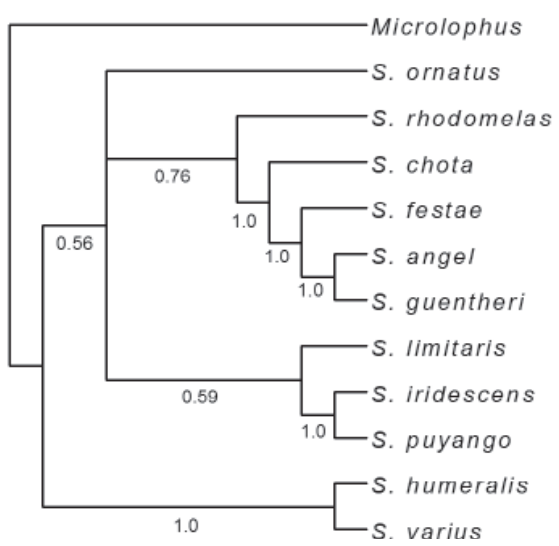

Figura 2. Seis hipótesis de relaciones filogenéticas entre las especies de Stenocercus de los Andes del norte basadas en análisis de parsimonia e inferencia bayesiana, detalladas en el texto. 
limitaris ( (S. angulifer, S. erythrogaster), (S. iridescens, $S$. puyango) )) ), (S. ornatus, S. rhodomelas) ))))) )— recibe un soporte moderado $(\mathrm{BP}=75)$ que es mayor que el soporte del mismo clado en el análisis anterior $(\mathrm{BP}=65)$. Asimismo, los únicos subclados con buen soporte $(\mathrm{BP}=$ 98) son los mismos que fueron descritos para el análisis anterior.

El análisis de parsimonia de los datos moleculares dio como resultado un árbol de 1657 pasos, con un índice de consistencia de 0.61 y un índice de retención de 0.43 (Fig. 2). De los 1641 caracteres moleculares, 919 son constantes y 462 parsimónicamente informativos. Pese a que este análisis fue realizado con menos especies que los análisis anteriores (véase métodos), la topología del árbol resultante sugiere nuevamente que las especies de Stenocercus de los Andes del norte están agrupadas en 2 clados, que corresponden a los mismos clados obtenidos a partir de los análisis de datos morfológicos (Fig. 2). A diferencia de los análisis anteriores, ambos clados en el árbol obtenido a partir de datos moleculares tienen buen soporte de bootstrap $(\mathrm{BP}=96$ y 100). Pero la diferencia más notable entre los árboles morfológicos y el árbol molecular está en la topología del clado que contiene la mayor parte de las especies - ( ( $(S$. rhodomelas $(S$. chota (S. festae (S. angel, S. guentheri) ))), (S. iridescens, $S$. puyango) ), (S. limitaris, $S$. ornatus $)-$. La posición de $S$. limitaris en relación a $S$. iridescens y $S$. puyango (especies hermanas) es diferente entre los árboles morfológicos y molecular, y sugiere que los datos moleculares no apoyan la monofilia de "Ophryoessoides" según Fritts (1974).

El análisis de parsimonia de todos los datos (i.e., 123 caracteres morfológicos y 1641 moleculares) dio como resultado un árbol 1834099 pasos, con un índice de consistencia de 0.60 y un índice de retención de 0.49 (Fig. 2). La matriz de datos combinados incluye 939 caracteres constantes y 539 parsimónicamente informativos. En general, la topología del árbol resultante de este análisis es muy similar a las topologías explicadas anteriormente. La topología del clado que contiene a $S$. haenschi y $S$. simonsii es idéntica a la obtenida con el análisis de parsimonia de todos los datos morfológicos (Fig. 2). Lo mismo sucede con el clado que contiene a $S$. trachycephalus y $S$. puyango. Sin embargo, la topología del clado que incluye a $S$. rhodomelas y $S$. festae es idéntica a la obtenida bajo el análisis de parsimonia de los datos moleculares (Fig. 2), con la adición de $S$. lache como especie hermana de $S$. festae $(\mathrm{BP}<50)$.

El análisis bayesiano de los datos moleculares se realizó bajo el modelo GTR $+I+\Gamma$ (Lanave et al. 1984, Tavaré 1986, Rodríguez et al. 1990). Los valores de verosimilitud de los 60000 árboles muestreados variaron entre -9600.586 y -9584.613 (media $=-9592.214)$. Los valores promedio de los parámetros estimados fueron: $\alpha=$ 0.65 ; proporción de sitios no variables $=0.323 ; \mathrm{r}(\mathrm{C}<->\mathrm{T})=$ $21.488, \mathrm{r}(\mathrm{C}<->\mathrm{G})=0.491, \mathrm{r}(\mathrm{A}<->\mathrm{T})=4.278, \mathrm{r}(\mathrm{A}<->\mathrm{G})=$ $16.45, \mathrm{r}(\mathrm{A}<->\mathrm{C})=5.174, \mathrm{r}(\mathrm{G}<->\mathrm{T})=1$; pi $\mathrm{A}=0.34$, pi $\mathrm{C}$ $=0.348$, pi $\mathrm{G}=0.114$, pi $\mathrm{T}=0.198$. La topología del árbol de compromiso resultante de este análisis es exactamente igual a la topología obtenida bajo el análisis de parsimonia de los datos moleculares (Fig. 2). Asimismo, los valores de probabilidades posteriores para cada rama son altamente congruentes con los valores de bootstrap del análisis de parsimonia; la única diferencia notable es que el clado que contiene a $S$. rhodomelas y $S$. angel parece tener mayor soporte bajo el análisis bayesiano.

Para el análisis bayesiano de datos moleculares y morfológicos combinados se dividieron los caracteres en 2 particiones. La primera partición incluyó los datos moleculares y fue analizada bajo el modelo GTR $+I+\Gamma$. La segunda partición incluyó los caracteres morfológicos y fue analizada bajo el modelo para caracteres morfológicos discretos Markov $k v(\mathrm{Mkv})$ propuesto por Lewis (2001), incorporando heterogeneidad en la tasa de evolución entre caracteres con la distribución gamma $(\mathrm{Mkv}+\Gamma)$. A diferencia de los árboles moleculares de parsimonia e inferencia bayesiana, el clado que contiene a $S$. ornatus y S. puyango en el árbol bayesiano con los datos combinados recibe bajo soporte $(\mathrm{PP}=0.56)$. Además, aunque con bajo soporte, la posición de $S$. limitaris en relación a $S$. ornatus es distinta, ya que no aparecen como especies hermanas sino que $S$. limitaris aparece como taxón hermano de $S$. iridescens y $S$. puyango.

\section{Discusión}

Los análisis filogenéticos realizados en este estudio revelanque tantocaracteres morfológicos comomoleculares apoyan la hipótesis de que las especies de Stenocercus de los Andes del norte están agrupadas en 2 clados mayores (Fig. 2). El primer clado incluye 13 especies-S. angulifer, S. angel, S. chota, S. erythrogaster, S. festae, S. guentheri, S. iridescens, S. lache, S. limitaris, S. ornatus, S. puyango, $S$. rhodomelas y $S$. trachycephalus-que se distribuyen desde el sur de Ecuador y norte del Perú hasta la costa del Caribe en Colombia y Venezuela (Fig. 1, Cuadro 1). Pese a que algunas especies de este clado habitan en tierras bajas (e.g., S. iridescens, S. erythrogaster), la mayor parte de las especies habitan en la cordillera de los Andes, especialmente en Ecuador (Fig. 1). El segundo clado mayor contiene 6 especies $-S$. bolivarensis, S. carrioni, S. haenschi, S. humeralis, S. simonsii y $S$. varius -que se distribuyen desde el sur de Ecuador hasta el sur de Colombia (Fig. 1, Cuadro 1). Todas las especies en este 
clado habitan en los Andes aproximadamente sobre los $1500 \mathrm{~m}$ de altitud, es decir, las principales diferencias en cuanto a la distribución geográfica de los 2 clados mayores de Stenocercus son: 1) el segundo clado es estrictamente andino $(>1.500 \mathrm{~m})$, mientras que el primero también incluye especies de tierras bajas, y 2) el primer clado tiene una distribución latitudinal mucho más amplia que el segundo (Fig. 1, Cuadro 1). Otro aspecto interesante de la distribución de Stenocercus en los Andes del norte es que no ha sido registrado para las cordilleras occidental y central (excepto por $S$. bolivarensis) de Colombia, cuya posible causa podría ser simplemente la falta de muestreo en estas zonas.

Los caracteres morfológicos apoyan la monofilia de "Ophryoessoides" según Fritts (1974) con muy buen soporte (Fig. 2). Por otro lado, pese a que $S$. angulifer y $S$. erythrogaster no fueron incluidas en el análisis molecular, la posición de $S$. limitaris en relación a $S$. iridescens y $S$. puyango (especies hermanas) demuestra que los datos moleculares no apoyan la monofilia de "Ophryoessoides", lo cual está de acuerdo con los resultados presentados por Torres-Carvajal et al. (2006). Esto sugiere que algunos de los caracteres morfológicos que apoyan la monofilia de "Ophryoessoides" en realidad son homoplásticos. Sin embargo, los resultados de este estudio están de acuerdo con las definiciones de "Ophryoessoides" y Stenocercus propuestas por Etheridge (en Peters y Donoso Barros, 1970): todas las especies del clado de 13 especies corresponderían a “Ophryoessoides", mientras que las especies del clado de 6 especies corresponderían a Stenocercus. En este trabajo no se proponen cambios taxonómicos ya que las especies de los Andes del norte no representan ni siquiera la mitad del número total de especies de Stenocercus.

Los Andes del norte $\left(12^{\circ} \mathrm{N}-5^{\circ} \mathrm{S}\right)$ se extienden desde el este de Venezuela hasta el norte del Perú por aproximadamente $2000 \mathrm{~km}$, y tienen una orientación NNE-SSO. Ciertos autores (Duellman, 1979; Jaillard et al., 2000) han reconocido las siguientes subregiones: cordilleras occidental, central y oriental en Colombia; nudo de Pasto (aproximadamente $100000 \mathrm{~km}^{2}$ de tierras altas en el sur de Colombia y norte de Ecuador); valles interandinos y cordilleras occidental y oriental en Ecuador. Los Andes del norte están separados de los Andes centrales por la depresión de Huancabamba (Aleman y Ramos, 2000; Jaillard et al., 2000). Los Andes son montañas muy jóvenes que aún están formándose, pero se calcula que las elevaciones actuales más altas se alcanzaron antes del Plioceno medio (Simpson, 1979; Aleman y Ramos, 2000). La resolución dentro de cada uno de los 2 clados mayores no es suficiente como para analizar la biogeografía histórica de Stenocercus en detalle. Sin embargo, es adecuado comentar acerca del clado $(S$. rhodomelas $(S$. chota (S. festae (S. angel, S. guentheri))) ), ya que esta topología fue inferida por todos los análisis que incluyeron datos moleculares (Fig. 2). Aunque este clado tiene una distribución latitudinal limitada (Fig. 1), su topología sería congruente con un patrón de especiación de sur a norte. Tomando en cuenta la reciente formación (de sur a norte) de los Andes del norte, es posible entonces que el alzamiento de esta cadena montañosa haya cumplido un rol fundamental en la evolución de Stenocercus. Es decir, el alzamiento de sur a norte de los Andes puede haber creado barreras geográficas, que junto con posibles eventos de dispersión fueron creando escenarios ideales para una secuencia de especiación de sur a norte en organismos andinos como Stenocercus. Esto requiere por supuesto que los linajes de Stenocercus que habitan en los Andes del norte se hayan originado al sur de esta región, lo cual ha sido sugerido con base en un análisis filogenético más completo de Stenocercus (Torres-Carvajal, 2007c). Sin embargo, para analizar esta posible secuencia sur a norte de especiación en más detalle, es necesario tener una hipótesis filogenética más robusta, para lo que sería ideal obtener datos moleculares de aquellas especies que habitan en el norte de Colombia. También hay que tomar en cuenta que la orogenia de los Andes es mucho más compleja que un simple alzamiento de sur a norte, y además es muy probable que la evolución de Stenocercus también haya sido afectada por los cambios climáticos del Pleistoceno.

\section{Agradecimientos}

Por el préstamo de especímenes, y en algunos casos sugerencias, agradezco a A. Almendáriz (EPN), F. Andreone (MZUT), C. Austin (LSUMZ), J. Campbell (UTA), R. Casallas Lasso (MLS), J. E. Castillo y J. M. Rengijo (IND-R), F. Castro (UV), L. A. Coloma (QCAZ), K. de Queiroz (USNM), L. Ford y D. Frost (AMNH), R. Günther (ZMB), J. Hanken y J. Rosado (MCZ), G. Köhler (SMF), J. D. Lynch (ICN), C. McCarthy (BMNH), J. A. McGuire (MVZ), M. Morales (UDAR), R. Nussbaum (UMMZ), M. P. Ramírez (UIS), T. Reeder y R. Etheridge (SDSU), J.-M. Touzet (FHGO), L. Trueb y R. Brown (KU), y H. Voris y M. Kearney (FMNH).

\section{Literatura citada}

Akaike H. 1973. Information theory and an extension of the maximum likelihood principle. In Second International Symposium on Information Theory, P. N. Petrov y F. Csaki (eds.). Akad. Kiado, Budapest. p. 267-81. 
Aleman, A. y V. A. Ramos. 2000. Northern Andes. In Tectonic evolution of South America, U. G. Cordani, E. J. Milani, A. Thomaz-Filho y D. A. Campos (eds.). Brazilian Academy of Sciences. Rio de Janeiro. p. 453-480.

Ayala, S. y F. Castro. 1982. Nueva especie de (Sauria: Iguanidae) lagarto collarejo de la zona sur andina de Colombia. Caldasia 13:473-478.

Ávila-Pires, T. C. S. 1995. Lizards of Brazilian Amazonia (Reptilia: Squamata). Nationaal Natuurhistorisch Museum Zoologische Verhandelingen 299:1-706.

Cadle, J. E. 1991. Systematics of lizards of the genus Stenocercus (Iguania: Tropiduridae) from northern Perú: New species and comments on relationships and distribution patterns. Proceedings of the Academy of Natural Sciences of Philadelphia 143:1-96.

Cadle, J. E. 1998. New species of lizards, genus Stenocercus (Iguania: Tropiduridae), from western Ecuador and Peru. Bulletin of the Museum of Comparative Zoology 155:257297.

Cadle, J. E. 2001. A new species of lizard related to Stenocercus caducus (Cope) (Squamata: Iguanidae) from Peru and Bolivia, with a key to the "Ophryoessoides Group". Bulletin of the Museum of Comparative Zoology 157:183-222.

Corredor, V. 1983. Una nueva especie de Stenocercus (Sauria: Iguanidae) de la cordillera oriental de Colombia. Lozania 37:1-10.

Duellman, W. E. 1979. The herpetofauna of the Andes: Patterns of distribution, origin, differentiation and present communities. In The South American herpetofauna: its origin, evolution, and dispersal, Monograph 7, W. E. Duellman (ed.), University of Kansas Natural History Museum Lawrence, Kansas. p. 371-459.

Etheridge, R. y K. de Queiroz. 1988. A phylogeny of Iguanidae. In Phylogenetic relationships of the lizard families, R. Estes y G. Pregill (eds.), Stanford University Press, California. p. 283-367.

Felsenstein, J. 1985. Confidence limits on phylogenies an approach using the bootstrap. Evolution 39:783-791.

Fritts, T. H. 1974. A multivariate evolutionary analysis of the Andean iguanid lizards of the genus Stenocercus. San Diego Society of Natural History 7:1-89.

Frost, D. R. 1992. Phylogenetic analysis and taxonomy of the Tropidurus group of lizards (Iguania: Tropiduridae). American Museum Novitates 3033:1-68.

Frost, D. R. y R. Etheridge. 1989. A phylogenetic analysis and taxonomy of iguanian lizards (Reptilia: Squamata). Miscellaneous Publications University of Kansas Natural History Museum 81:1-65.

Frost, D. R., R. Etheridge, D. Janies y T. A. Titus. 2001a. Total evidence, sequence alignment, evolution of polychrotid lizards, and a reclassification of the Iguania (Squamata: Iguania). American Museum Novitates 3343:1-38.

Frost, D. R., M. T. Rodrigues, T. Grant y T. Titus. $2001 \mathrm{~b}$. Phylogenetics of the lizard genus Tropidurus (Squamata: Tropiduridae: Tropidurinae): Direct optimization, descriptive efficiency, and sensitivity analysis of congruence between molecular data and morphology. Molecular Phylogenetics and Evolution 21:352-371.
Harvey, M. B. y R. L. Gutberlet, Jr. 2000. A phylogenetic analysis of the tropidurine lizards (Squamata: Tropiduridae), including new characters of squamation and epidermal microstructure. Zoological Journal of the Linnean Society 128:189-233.

Jaillard, E., G. Hérail, T. Monfret, E. Díaz-Martínez, P. Baby, A. Lavenu y J. F. Dumont. 2000. Tectonic evolution of the Andes of Ecuador, Peru, Bolivia, and northernmost Chile. In Tectonic evolution of South America, U. G. Cordani, E. J. Milani, A. Thomaz-Filho y D. A. Campos (eds.). Brazilian Academy of Sciences. Rio de Janeiro. p. 481-559.

Kluge, A. G. y J. S. Farris. 1969. Quantitative phyletics and the evolution of anurans. Systematic Zoology 18:1-32.

Kumazawa, Y. y M. Nishida. 1993. Sequence evolution of mitochondrial tRNA genes and deep-branch animal phylogenetics. Journal of Molecular Evolution 37:380-398.

Lanave, C., G. Preparata, C. Saccone y G. Serio. 1984. A new method for calculating evolutionary substitution rates. Journal of Molecular Evolution 20:86-93.

Lehr, E. 2002. Amphibien Und Reptilien in Peru. Die Herpetofauna Entlang Des 10. Breitengrades Von Peru: Arterfassung, Taxonomie, Ökologische Bemerkungen Und Biogeographische Beziehungen. Natur und Tier, Münster.

Lewis, P. O. 2001. A likelihood approach to inferring phylogeny from discrete morphological characters. Systematic Biology 50:913-925.

Macey, J. R. y A. Verma. 1997. Homology in phylogenetic analysis: Alignment of transfer RNA genes and the phylogenetic position of snakes. Molecular Phylogenetics and Evolution 7:272-279.

Macey, J. R., A. Larson, N. B. Ananjeva, Z. Fang y T. J. Papenfuss. 1997. Two novel gene orders and the role of light-strand replication in rearrangement of the vertebrate mitochondrial genome. Molecular Biology \& Evolution 14:91-104.

Maddison, D. R. y W. P. Maddison. 2001. MacClade: Analysis of phylogeny and character evolution, version 4.03. Sinauer, Sunderland, Massachusetts.

Nylander, J. A. A. 2005. MrModeltest, version 2.2. Uppsala University.

Peters, J. A. y R. Donoso-Barros. 1970. Catalogue of the neotropical Squamata: Part II. Lizards and amphisbaenians. United States National Museum Bulletin 297:1-293.

Rambaut, A. y A. J. Drummond. 2003. Tracer, version 1.2. $<$ http://evolve.zoo.ox.ac.uk>

Rodríguez, F., J. L. Oliver, A. Marín y J. R. Medina. 1990. The general stochastic model of nucleotide substitution. Journal of Theoretical Biology 142:485-501.

Ronquist, F. y J. P. Huelsenbeck. 2003. MrBayes 3: Bayesian phylogenetic inference under mixed models. Bioinformatics 19:1572-1574.

Schulte, J. A., II, J. R. Macey, A. Larson y T. J. Papenfuss. 1998. Testing the monophyly of four iguanid subfamilies: a comparison of molecular and morphological data. Molecular Phylogenetics and Evolution 10:367-376.

Schulte, J. A., II, J. P. Valladares y A. Larson. 2003. Phylogenetic relationships within Iguanidae inferred using molecular and morphological data and a phylogenetic taxonomy of iguanian lizards. Herpetologica 59:399-419. 
Simpson, B. B. 1979. Quaternary biogeography of the high montane regions of South America. In The South American herpetofauna: Its origin, evolution, and dispersal, W. E. Duellman (ed.), University of Kansas Natural History Museum Monograph 7, Lawrence, Kansas. p. 157-188.

Swofford, D. L. 2003. PAUP*. Phylogenetic Analysis Using Parsimony* (and other methods), version 4.0. Sinauer, Sunderland, Massachusetts.

Swofford, D. L. y S. H. Berlocher. 1987. Inferring evolutionary trees from gene frequency data under the principle of maximum parsimony. Systematic Zoology 36:293-325.

Tavaré, S. 1986. Some probabilistic and statistical problems in the analysis of DNA sequences. Lectures on Mathematics in the Life Sciences 17:57-86.

Thiele, K. 1993. The holy grail of the perfect character: The cladistic treatment of morphometric data. Cladistics 9:275-304.

Thompson, J. D., T. J. Gibson, F. Plewniak, F. Jeanmougin y D. G. Higgins. 1997. The ClustalX windows interface: flexible strategies for multiple sequence alignment aided by quality analysis tools. Nucleic Acids Research 24:4876-4882.

Torres-Carvajal, O. 2000. Ecuadorian lizards of the genus Stenocercus (Squamata: Tropiduridae). University of Kansas Natural History Museum Scientific Papers 15:1-38.

Torres-Carvajal, O. 2005a. A new species of iguanian lizard (Stenocercus) from the western lowlands of southern Ecuador and northern Peru. Herpetologica 61:78-85.

Torres-Carvajal, O. 2005b. New Species of Stenocercus (Squamata: Iguania) from the Andes of Central Peru with a Redescription of Stenocercus variabilis. Journal of Herpetology 39:471-477.

Torres-Carvajal, O. 2005c. A new species of Stenocercus
(Squamata, Iguania) from central-western Brazil with a key to Brazilian Stenocercus. Phyllomedusa 4:111-120.

Torres-Carvajal, O. 2005d. Phylogenetic systematics of South American lizards of the genus Stenocercus (Squamata: Iguania). Disertación doctorado, Department of Ecology and Evolutionary Biology, The University of Kansas. Lawrence, Kansas. 464 p.

Torres-Carvajal, O., J. A. Schulte y J.E. Cadle. 2006. Phylogenetic relationships of South American lizards of the genus Stenocercus (Squamata: Iguania): A new approach using a general mixture model for gene sequence data. Molecular Phylogenetics and Evolution 39:171-185.

Torres-Carvajal, O. 2007a. A taxonomic revision of South American Stenocercus (Squamata: Iguania) lizards. Herpetological Monographs. 21:76-78.

Torres-Carvajal, O. 2007b. A new species of iguanian lizard (Iguania: Stenocercus) from the Andes of Colombia. Copeia 2007:56-61.

Torres-Carvajal, O. 2007c. Phylogeny and biogeography of a large radiation of Andean lizards (Squamata: Stenocercus). Zoologica Scripta 36:311-326.

Wiens, J. J. 1995. Polymorphic characters in phylogenetic systematics. Systematic Biology 44:482-500.

Wiens, J. J. 2000. Coding morphological variation within species and higher taxa for phylogenetic analysis. In Phylogenetic analysis of morphological data, J. J. Wiens (ed.). Smithsonian Institution Press, Washington D.C. p. 115-145.

Wiens, J. J. 2001. Character analysis in morphological phylogenetics: Problems and solutions. Systematic Biology 50:689-699. 
Apéndice 1. Especímenes examinados

Microlophus occipitalis. ECUADOR: Provincia Guayas: Playas, 2³8’0”S, 80²3’0”W, KU 142715, 142717, 142719, 142723.

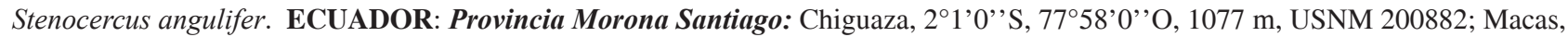

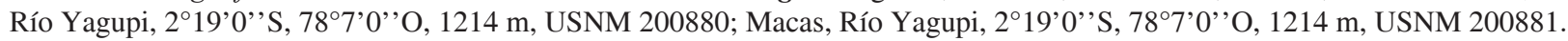

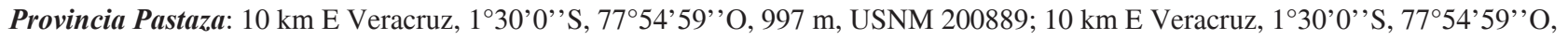
997 m, USNM 200890; 2.5 km downstream Río Bobonaza headwaters, 1²8'0'’s, 7753'0'’O, 652 m, USNM 200885; 3 km S

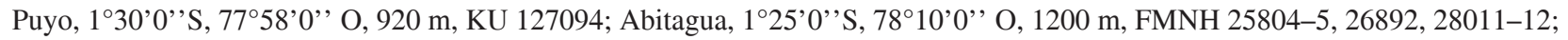

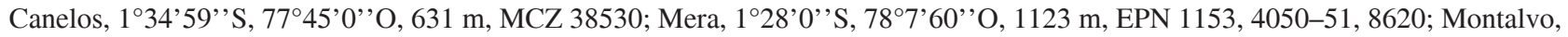

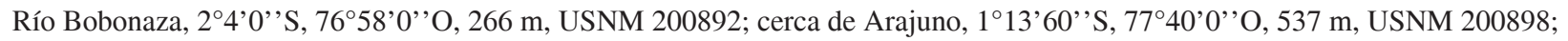
Palanda, E Sarayacu, 144'0' S, 77²9'0', O, USNM 200897; Puyo, 1²8'0' 'S, 7758'59', O, 981 m, USNM 200891; Puyo, Santana, EPN 6499, 6505; Río Bobonaza headwaters, $1^{\circ} 28^{\prime} 0^{\prime}$ 'S, 7753'0' O, USNM 200886-8; Río Licuna, tributary of Río Villano, USNM 200896; Río Liguino, USNM 200899; Río Oglán Alto, USNM 200893; Río Pastaza, Alpayaca, MCZ 8061; Río Pucuyacu, USNM 200895; Río Solís, EPN 5902-4; Río Villano, USNM 200894; Veracruz, 1³0’0’'S, 7756'0’’O, 950 m, KU 121092. Provincia Tungurahua: Río Negro, $1^{\circ} 24^{\prime} 0^{\prime}$ 'S, $78^{\circ} 12^{\prime} 0^{\prime}$ 'O, QCAZ 1635. Localidad no especificada: AMNH 5821, ZMB 16594. PERÚ: Departamento La Libertad: Pampa Seca, Río Mixiollo valley, upper Huallaga region, AMNH 57085. Departamento Loreto: front range btw Moyobamba \& Cahuapanas, 1000 m, AMNH 57083; Icuta, on trail Balsapuerto-Moyobamba, 1061 m, AMNH 56413. Departamento San Martín: Moyobamba, 6²'60'’ S, 76 58'0'ㅇ, 723 m, BMNH 1946.8.12.33-34 (sintipos).

Stenocercus angel. COLOMBIA: Departamento Nariño: 2 km S Tangua, 14'45' 'N, 77²4'53'’O, 2300 m, ICN $4218 ; 3$ km N

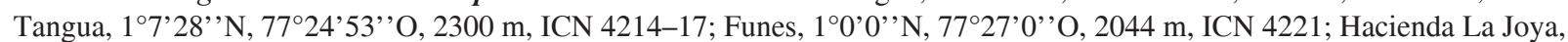
NE Funes, ICN 4219; La Joya, Funes, $1^{\circ} 0^{\prime} 0$ '’ N, 77²7'0'’O, 2044 m, MCZ 159591-2; Laguna de Cumbal, ICN 2227; Pasto, $1^{\circ} 12^{\prime} 49^{\prime}$ 'N, 77¹6' 52'’ O, 3040 m, ICN 4220; localidad no especificada, ICN 4222-3, 9041-3, UV 11167, UV 11169. ECUADOR: Provincia Carchi: $10 \mathrm{~km}$ ONO El Carmelo, $0^{\circ} 42^{\prime} 5^{\prime \prime}$ 'N, 7743'0'’O, $3182 \mathrm{~m}$, USNM 201218-9; 13.6 km O Tulcán on road

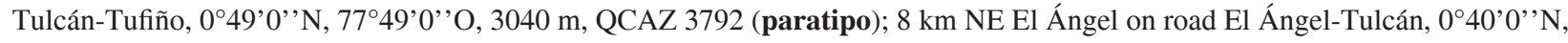
7752'0' 'O, 3560 m, 3732 (paratipo), 3733 (holotipo), 4117-9 (paratipos); ca. $2 \mathrm{~km}$ (by road) SO of Cocha Seca, 0³8'25' 'N,

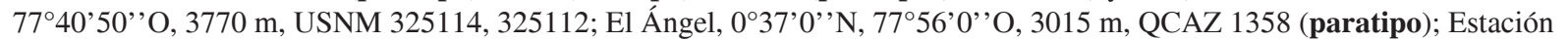
Biológica Guanderas, QCAZ 3777 (paratipo). Provincia Sucumbíos: Caldera of Páramo Mirador, 3700 m, USNM 325113; El Playón de San Francisco, 0³7’59’’N, 77³7’0’’O, 3300 m, QCAZ 1322 (paratipo).

Stenocercus bolivarensis. COLOMBIA: Departamento Cauca: Bolívar, 158'15'’N, 7658'10’’O, 1101 m, MCZ 151477; Municipio Bolívar, 1800 m, AMNH 130551; surroundings of Municipio Bolívar, 150’0'`N, 7658'0' 'O, 1650-1750 m, ICN 4205 , 4207-9 (paratipos), 4210 (holotipo), 4211 (paratipo), KU 181994, 182812 (paratipo), UV 5152, 13983.

Stenocercus carrioni. ECUADOR: Provincia El Oro: Llano de Guavos, Cordillera Chilla, AMNH 18308. Provincia Loja: $10 \mathrm{~km}$ N Celica, 4³'0''S, 7958'0' 'O, 1900 m, MCZ 93589; Alamor, 42'0'’S, 80²'0' O, 1325 m, AMNH 21847, 22136-7, 22140, 22154, 22156, 22169-70, 22172-3, 22175, 22177, 22187, 22192-7, 22199, 22201-2, 22207-8, 22210; Guainche, 8 km S Alamor, $4^{\circ} 6^{\prime} 20^{\prime}$ 'S, 80²'0' 'O, AMNH 22120; Río Lunamá, E Cerro Guachanamá, AMNH 22185; Seboyal, 8 km NO Alamor, 359'0' 'S, $80^{\circ} 5^{\prime} 0^{\prime}$ 'O, AMNH 21848.

Stenocercus chota. ECUADOR: Provincia Carchi: Valle del Chota, USNM 201161-72, 201175-8, 201180-1, 201183-4, 2011879, 201194-6; La Concepción, 0`35'0' 'N, 787'0'’O, 1575 m, MZUT R2154.1-5, R2154.25-29 (paratipos); Río Chota, cerca de village El Chota, 0²8'0', N, 784'0' O, 1580 m, USNM 211338, 211340, 211345, 211347, 211349. Provincia Esmeraldas: Río Cachabí, EPN 5858-5860, 5862-5864 (paratipos). Provincia Imbabura: 5 km E Chota on Panamerican hwy, 0²8'0' 'N, 78¹'0' 'O, QCAZ 2768 (paratipo), 3755 (paratipo), 3757 (paratipo), 3762-3767 (paratipos), 3769-3776 (paratipos), 3768 (holotipo); 6.5 km E Panamerican hwy on road Ambuquí-Monte Olivo, 0²5'0’’ N, 7755'0’’O, 1940 m, QCAZ 806, 897-902, 3791, 3794 (paratipos); Ambuquí, 0²7'0'’N, 78¹'0'’O, 1780 m, QCAZ 799 (paratipo); Chota, 0²8'0'”N, 784'0' O, QCAZ 2654-5, 27732778 (paratipos); El Juncal, Valle del Chota, USNM 201197, 201200, 201202, 201204; Palma Real, 0²0'0' N, 7856'0' 'O, 574 m, USNM 201131-2; Salinas, $0^{\circ} 30^{\prime} 0^{\prime}$ 'N, 78 8'0' O, QCAZ 4162; Tumbabiro, 0²8'0' 'N, 78 $12^{\circ} 0^{\prime}$ ' O, QCAZ 4161; surroundings of Yaguarcocha, EPN 5848 (paratipo).

Stenocercus erythrogaster. COLOMBIA: Departamento Bolívar: Carmen de Bolívar, 943'20' 'N, 757'59' 'O, 153 m, ICN 4224; San Juan Nepomuceno, Vereda Los Chivos, 9'57'24'’N, 755'12'O, 142 m, ICN (number not assigned). Departamento El César: El Limón, 9³4'0' 'N, 740'0' 'O, 91 m, ICN 7950, 7973; La Victoria de San Isidro, 9³5'7' 'N, 73¹1'8' 'O, 393 m, ICN 7970, 7972; Santa Marta mountains, Valencia, $10^{\circ} 18^{\prime} 0^{\prime}$ 'N, $73^{\circ} 24^{\prime} 0^{\prime}$ 'O, 182 m, UMMZ 54740. Departamento Magdalena: Parque Nacional 


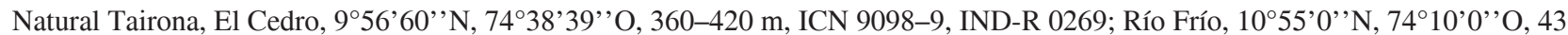

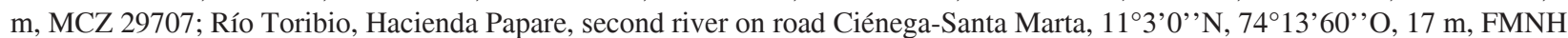
165153; Santa Marta mountains, MCZ 11303; Santa Marta mountains, between Mamatoca and La Tigrera, UMMZ 45468; Santa Marta mountains, cerca de Bolívar, 10²0'60'’N, 749'0'’O, 125 m, UMMZ 54739; Santa Marta mountains, Río Tamocal, UMMZ 45466.

Stenocercus festae. ECUADOR: Provincia Azuay: $1 \mathrm{~km}$ SE Cuenca, 254'0'’S, 7859'0’’O, USNM 20121-3; 3.2 km E Sigsig,

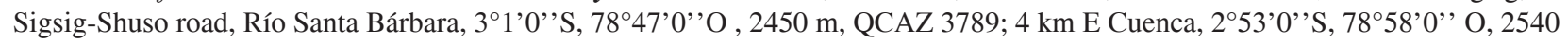
m, KU 134574-134579, 134582, 134583, 134585-134592, 134594; 4 km O San Cristóbal, 2 250'0' 'S, 7852'0' 'O, 2500 m, KU

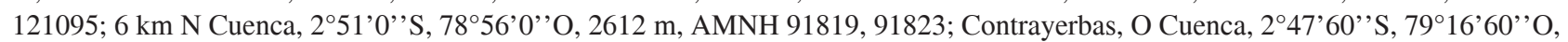
3957 m, AMNH 23439, 23441-4; Cuenca, 253'0' 'S, 7859'0' O, 2530 m, UDAR 11, USNM 201208-10; Sigsig, 3³'0' 'S, 78`48'0' 'O, QCAZ 5599; Laguna Zurucuchu, 3200 m, KU 121094; Sevilla de Oro, 0248' S, 78³9'O, 2630 m, QCAZ 4059 (neotype); Sigsig-Shiguinda road, 3200 m, QCAZ 1337; Sinincay, 2॰49'60'’S, 790'0'’O, 2515 m, AMNH 23416, 23419, 23421, 23436, 23448-53; Ucubamba, 02 52' S, 7854'O, 2530 m, UDAR 5; localidad no especificada, USNM 201222-3. Provincia Cañar:

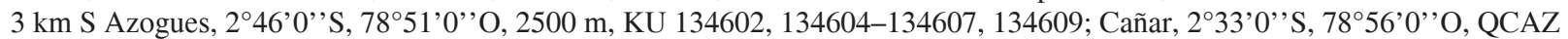

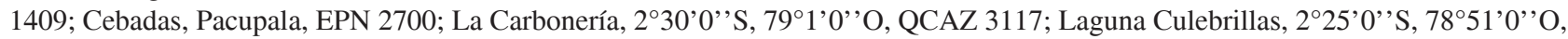
QCAZ 1346-48. Provincia El Oro: Salvias, 345'0'’ S, 7940'0' O, 1050 m, AMNH 18313-4. Provincia Loja: 14 km NE Urdaneta,

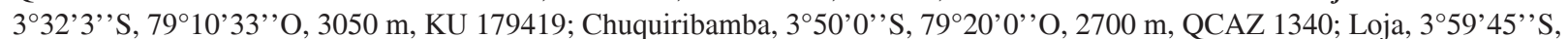
79¹1'58', O, 2064 m, QCAZ 1367; Loja-Zamora road, QCAZ 5526-7; Manú, 3²9'0'’S, 79²4'0' 'O, 2200 m, QCAZ 3599-602; Saraguro, 336'0' 'S, 79¹3'0''O, 2500 m, KU 134120, 134122-134126, QCAZ 3113. Provincia Zamora-Chinchipe: Cajanuma, Sendero Mirador, QCAZ 4039. Localidad no especificada: Llapín, 8 km S Mollendo, 3151 m, AMNH 23422-4.

Stenocercus guentheri. ECUADOR: Provincia Chimborazo: $14.5 \mathrm{~km}$ N Tixán on Panamerican Highway, 2³'0' 'S, 7844'0' 'O, 3200 m, QCAZ 3659-61. Provincia Cotopaxi: Panamerican Highway cerca de Parque Nacional Cotopaxi, 3200 m, FHGO 629; Parque Nacional Cotopaxi, ca. 4000 m, QCAZ 1109. Provincia Imbabura: 7.5 km N Otavalo on Panamerican Highway, QCAZ 3761; Atuntaqui, 0²0'1'’N, 78¹8'8'’O, 2387 m, QCAZ 776; Tabacundo-Mojanda road, 3150 m, QCAZ 3793. Provincia

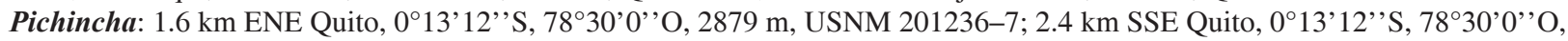
2879 m, USNM 201234, 201238; Cayambe, SMF 11162; Cayambe volcano slopes, 0²'10' 'N, 7759'30' 'O, 3500 m, FHGO 1136; Guayllabamba, 0³'20'’S, 78²0'25'O, 2139 m, QCAZ 718, 777, 779, 782; Ilaló, Hacienda Chuspiyacu, QCAZ 722; Illiniza Sur,

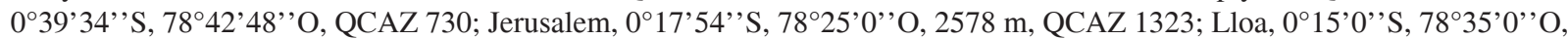
3060 m, QCAZ 4108; Machachi, 0³0'28'’S, 78³3'46' O, 2940 m, QCAZ 720, 736, 758, 775, 778, 780-1, 783-4; below Pacto,

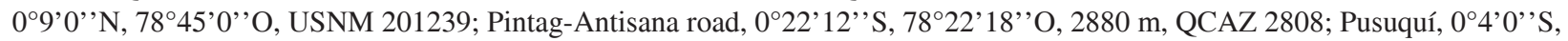
78²7'0' 'O, 2747 m, QCAZ 4153; Quito, 0¹1'22'’S, 78²9'38'’O, 2810 m, EPN 5900, QCAZ 432, 728, 737, 2857, SMF 60592, USNM 201226, 201230-3; San Antonio, 0¹'0''S, 78 27'9', O, QCAZ 713-6, 738, 740-54, 1357, 1400, 2163, 2199, BMNH 58.7.25.16, 58.7.25.16a, 58.7.25.18, 59.9.20.6, 60.6.16.18, 60.6.16.20-21 (sintipos); Uyumbicho, 0²3'0''S, 78 31'0' 'O, QCAZ

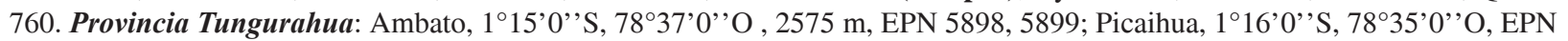
5887-5889; Urbina, 0²'54'’S, 7846'21'’O, QCAZ 2858. Localidad no especificada: FHGO 522, 852, 1493, SMF 53199.

Stenocercus haenschi. ECUADOR: Bolívar: Balsapamba, 146'0'’S, 79¹1'0’’O, 750 m, ZMB 16595 (holotipo).

Stenocercus humeralis. ECUADOR: Provincia Loja: 2 km E Loja, 40'0'’S, 79¹1'55' 'O, 2200 m, KU 121137; 2.7 km E Loja on road NE Zamora road, 40'0''S, 79¹1'32'’O, 2135 m, KU 141162; $12.2 \mathrm{~km}$ S Loja, Río Malacatos valley on road to Vilcabamba,

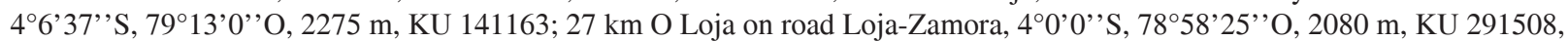
QCAZ 5524; 5 km N Loja, 357'17'’S, 79¹3'0' 'O, 2150 m, KU 134003, 134005; 6 km N Loja, 357'17' 'S, 79¹3'0'’O, 2150 m, KU 134005; Catamayo-Jimbilla road, EPN 5824-43; Loja, 40'0'’S, 79¹2'0' 'O, 2064 m, BMNH 1946.8.11.76 (sintipo), EPN 1343, 5807-8, 5810-3, 5815, FHGO 1494-5, KU 121136, 121138, 134000, 134002; Malacatos, EPN 1270, 5809.

Stenocercus iridescens. COLOMBIA: Departamento Nariño: Boca Grande, Tumaco, 147’55' 'N, 7848’56’'O, 0 m, ICN 4225. ECUADOR: Provincia Azuay: Tamarindo, FHGO 416. Provincia Chimborazo: Chimbo bridge, cerca de Bucay, $2^{\circ} 41^{\prime} 0^{\prime \prime} \mathrm{S}$,

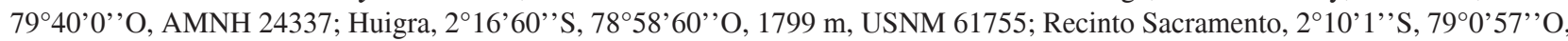
1566 m, QCAZ (number not assigned). Provincia Cotopaxi: La Maná, 055'60'’S, 79¹3'0'’O, 889 m, QCAZ $2767,3052$.

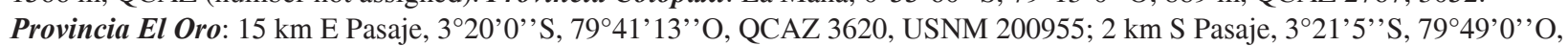
100 m, USNM 200946; Pasaje, 3¹9'60'’S, 7949'0'’O, 105 m, AMNH 21861-2, 21867-8, 21975-8, 21987-1; Piñas, 340'0'’S, 79³9'0'’O, 876 m, FHGO 1089; Río Jubones, AMNH 21944; road Santa Rosa-Chonta, AMNH 22121; Santa Rosa, 3²7’0'’S,

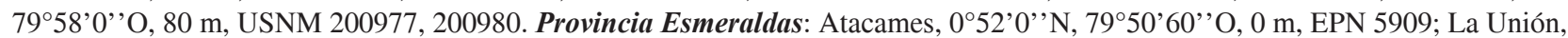
049'0'’N, 7952'0'’ O, 49 m, FHGO 97; Río Tiaone EPN 5906, 5908; Same, 049'20'’N, 7959'38'’ O, 0 m, QCAZ 721; Tonsupa,

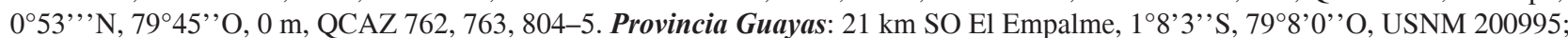
5 km E Milagro, 27'0',S, 79³3'18' O, USNM 200984; Balzar, 1²2'0'’S, 7954'0'’O, 59 m, EPN 5925-5927, 5929-5931; Cerro 
BlancoAMNH 13510, 22184, 22221, USNM 200992; Milagro, 27'0'’S, 79³5'60'”, 71 m, U, EPN 5005, 5007-5009; Guayaquil,

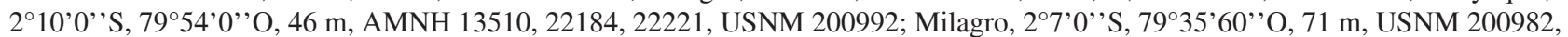
200989. Provincia Imbabura: 1 km E Apuela, 0²1'0'’N, 78²9'28'’ O, 1950 m, USNM 200902; 1 km SO Peñaherrera, 0²0'37' N,

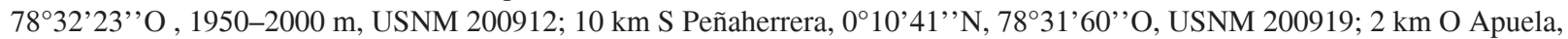
0²1'0'’N, 78³1'5'’O, 1850 m, USNM 200911; 3 km SO Peñaherrera, 0¹9'51' 'N, 78³3'9', O, 1825 m, USNM 200914; Apuela,

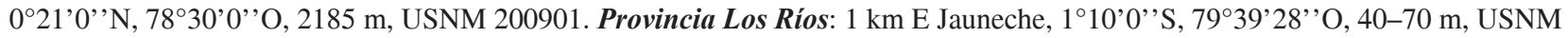
285780; Jauneche, 1 ${ }^{\circ} 10^{\prime} 0^{\prime}$ 'S, 7940'0' O, EPN 5004, USNM 222801; Patricia Pilar, 0³3'0' 'S, 79²2'0'’O, QCAZ 97; Quevedo, $1^{\circ} 2^{\prime} 0^{\prime}$ 'S, 79²7'0' 'O, 111 m, USNM 200934; Río Palenque, 0³5'0'’S, 79²2'0', O, QCAZ 431, 2205, 2206, 2212; Ventanas,

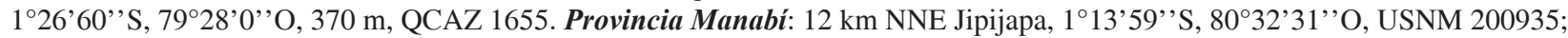

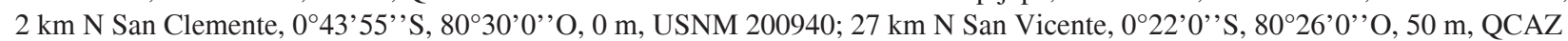
3329, 3330, 3343; $4 \mathrm{~km}$ O Calceta, 0`51'0' 'S, 80¹2'9' ' O, USNM 200936; 9 km N San Vicente, 0³0'7' 'S, 80²4'0', O, 0 m, USNM 200942-3, 200945; 32 km N San Vicente on road San Vicente-Pedernales, 00²0'0' 'S, 80²1'0' O, 183 m, QCAZ 3314 ;

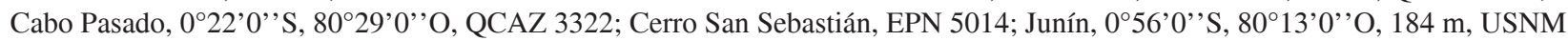
200939; Puerto Rico, 1³7’0’’S, 8050’0’’ O, 123 m, QCAZ 1634. Ecuador occidental: BMNH 60.6.16.2-4 (sintipos).

Stenocercus lache. COLOMBIA: Departamento Boyacá: Guicán, 6²7’55’’N, 72²4'54’’O, 2908 m, ICN 6712; Parque Nacional Natural El Cocuy, eastern flank Río Lagunillas, 13 km SE Municipio El Cocuy, 4000 m, IND-R 3054-63; Parque Nacional Natural El Cocuy, Trail La Esperanza-Púlpito del Diablo, close to Quebrada Pantanogrande (tributary of Río Nevado), 6¹9'0' 'N, 72²0'0' 'O, 3700-4000 m, ICN 5749 (holotipo), 5750-62 (paratipos); Sierra Nevada del Cocuy, Finca La Esperanza, IND-R 2178; Sierra Nevada del Cocuy, páramo Concavo, 3700 m, IND-R 550.

Stenocercus limitaris. ECUADOR: Provincia El Oro: Salvias, 345'0'’ S, 7940'0' 'O, 1050 m, AMNH 18311 (paratipo). Provincia Loja: $12.8 \mathrm{~km}$ N Alamor, 355'3''S, 80¹'60', O, 1097 m, AMNH 22215 (paratipo); Alamor, 4¹'60' 'S, 80¹'60'O, 930 m, AMNH 18319, 22113-8, 22131-2, 22158-62, 22165-7, 22178-82, 22223-9 (paratipos); Cruzpamba, 4¹0'0' 'S, 80¹'0' O, 1000 m, MCZ 85083 (paratipo). PERU: Departamento Piura: Toronche, base of Cerro Ayapate, ca. 16 km (airline) SE Ayabaca, 4³5'0'’S, 79³2'0' 'O, 1950-2100 m, MCZ 182245-8 (paratipos).

Stenocercus ornatus. ECUADOR: Provincia Loja: $10.6 \mathrm{~km} \mathrm{~S}$ Yangana, 4²7'0'’S, 799'20'’O, $2190 \mathrm{~m}$, QCAZ 3790; 1-1.5 km E Loja, USNM 201270-1, 201273; 12 km O Loja, KU 134148; 15 km O Loja, 359'48' 'S, 79¹5'18' 'O, KU 134140-134144, 134149; 2 km E Loja, 359'23'’S, 79¹0'42' 'O, 2200 m, KU 121127, 121129-121134; 3 km E Loja, 359'23' 'S, 79¹0'42'’O, USNM 201276-8; 3 km O Loja, 40'14'’S, 79¹2'49'’O, 2150 m, KU 134127, 134129-134131, 134134, 134138, 134139; 4 km O Loja on road to Catamayo, 40'36',S, 79¹3'12'”O, 2280 m, KU 141167; 4.6 km N Loja, 356'8',S, 79¹3'34'”O, 2065 m, KU 141168-141170; $5 \mathrm{~km}$ N Loja, 356'0'’S, 79¹3'33'’O, KU 134150, 134151, 134153, 134154; $6 \mathrm{~km}$ S Loja on road to Vilcabamba, 44'21'’S, 79¹1'53' 'O, 2300 m, FHGO 585; Celica, 47'0'’S, 7957'0'’O, 1552 m, AMNH 18318; Cerro Uritusinga, 3000 m, QCAZ 2020; Cerro Villonaco, EPN 3540, QCAZ 2020; Loja, 40'0'’S, 79¹2'0' 'O, 2150 m, BMNH 1946.8.29.72 (holotipo), KU 121126, QCAZ 6088-93; Purunuma, slopes of Cerro Colambo, 4²12'0''S, 79²4'0'’O, 2464 m, QCAZ 5532; San Bartolo, 12.8 km NE Alamor, 42'0' 'S, 80²'0' 'O, 2273 m, AMNH 22213; Vilcabamba, 4¹5'0' 'S, 79¹5'0'’ O, 1500 m, FHGO 405, 679, 1161 ; localidad no especificada, EPN 5877-5880.

Stenocercus puyango. ECUADOR: Provincia El Oro: 19 km N Alamor, 355'12'’S, 80¹'26' 'O, QCAZ 6355 (paratipo); Bosque Protector Puyango, 352'55', S, 804'59' 'O, QCAZ 6356 (paratipo); Puyango, 353'0' 'S, 804'47' O, 300 m, QCAZ 6701-3, 6705-13, 6715-19, 6721-22 (paratipos), 6723 (holotipo), 6724-5 (paratipos). Provincia Loja: 3 km SO Malacatos, 4¹3’31’'S, 79¹6’3' O, 1500 m, MCZ 85086, 131823. No specific political unit: Río Puyango, AMNH 21934-6 (paratipos). PERU: Departamento Lambayeque: $21 \mathrm{~km}$ E, 7 km N Olmos, 5'55'17'’S, 79³3'20'” O, 700 m, MVZ 82364 (paratipo). Departamento Tumbes: Quebrada Faical E El Caucho, 24 km SE Pampa de Hospital, 349'0',S, 80¹6'0'’ O, LSUMZ 26989, 39446, 39451 (paratipos). Localidad no especificada: FMNH 81450. Localidad no especificada: AMNH 22186 (paratipo).

Stenocercus rhodomelas. ECUADOR: Provincia Azuay: 1.1-2.7 km S O Cataviña, 1310 m, KU 152188; 1.6 km O Minas at Río Minas, 317'6' 'S, 79²0'57' 'O, 1410 m, KU 152178, 152179; 12 km SO Girón, 314'0' 'S, 79¹3'0' 'O, 2000 m, USNM 201285; 2.7-3.5 km SO Cataviña, 1250 m, KU 152185, 152187; 4.8 km O Abdón Calderón, 3¹6'25'’S, 79¹8'23'”, 1435 m, KU 152183;

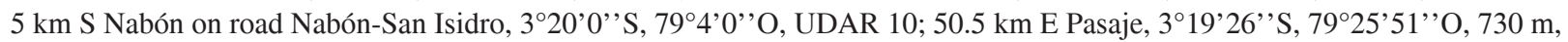
KU 152177; 7-8 km O Girón, 3¹2’0' 'S, 79¹0’0' 'O, 2100 m, USNM 201280-1; ca. 11 km O Santa Isabel, Río Jubones drainage, $3^{\circ} 16^{\prime} 44^{\prime}$ 'S, 79²1'52' 'O, 1480 m, AMNH 110599-603; ca. 4 km E San Francisco, km 109 on Cuenca-Machala hwy, 1250 m, USNM 201288, 201293, 201296-8; Girón, 3¹0'0' 'S, 798'0' 'O, EPN 3510, 3512; Girón, cerca de Piedra Labrada, EPN 3532; Oña, 327'0'’S, 79¹0'0'’O, 2522 m, BMNH 1946.8.29.77-78 (sintipos); N Oña, 1885 m, KU 141164, 141166; Río León, 11.8 km N Buenos Aires, 325'16' 'S, 799'37' 'O, 1940 m, KU 202945, 202946; Río León, 12.5 km N Oña, 3²5'16' 'S, 799'37' O, 1920 m, KU 142699-142701; Santa Isabel, 3¹6'0'’S, 79¹9'0' O, QCAZ 3076, 5645, USNM 201305-8, 201310, 201316; Valle de Yunguilla, Chalcápac, 1550 m, QCAZ 3663. Provincia Loja: San José, QCAZ 6095; Valle de Casanga, EPN 3507, $5910-5921$. 
Stenocercus simonsii. ECUADOR: Provincia Azuay: 3.3 km NE Girón, 38'44'’S, 796'44'’'O, 2255 m, KU 152189-90; Girón, $3^{\circ} 10^{\prime} 0^{\prime}$ 'S, 797'59' 'O, 2240 m, KU 134157-64; Oña, 3²7'0'’ S, 79¹0'0' O, 2522 m, BMNH 1946.8.11.73 (sintipo). Provincia Loja: Saraguro, 3³5'59'’S, 79¹3'0'’O, 2500 m, KU 134165-74.

Stenocercus trachycephalus. COLOMBIA: Departamento Boyacá: Aquitania, 5³1'11'’N, 7253'15' 'O, 3216 m, ICN 2821; Laguna de Tota, Las Cintas, 537'0' 'N, 72 52'0' 'O, 3524 m, ICN 1520-1; Moniquirá, 552'60' 'N, 73³4'29' 'O, 1780 m, ICN 2414; Paz del Río, 5'59'17' 'N, 72 45'8' 'O, 2365 m, ICN 691; San José de la Montaña, 3000 m, ICN 2853. Departamento Cundinamarca: Arrayán, 4³3'26' 'N, 7356'2' 'O, 1749 m, ICN 1234; Arrayán, 4³3'26'’N, 7356'2' 'O, 1749 m, ICN 1235; Bogotá, 4³5'60' 'N, 744'60' 'O, 2619 m, ICN 495, 1496, 2752, 2820, 2838, 4212-3, 4524, IND-R 312, 1097, USNM 75958, 90064, 92493, 95178, 153973; Bogotá, km 4 Suba-Cota, ICN 5732; Bogotá, páramo de Granizo, ICN 5934; Bogotá, Río Chicó, 2700-2800 m, ICN 1238-46; Guatavita, 456' 13' 'N, 7349'57' 'O, 2717 m, ICN 1519; Iguaqué Flora and Fauna Sanctuary, 3.5 km SE Arcabuco, 3300 m, IND-R 3051-2; km 11 road Bogotá-Choachi, 3000-3200 m, IND-R 262; NO Bogotá, UTA 3425-7; Páramo de Chingaza, ICN 2303, 2306; Parque Nacional Natural Chingaza, La Playa, 4³2’21'’N, 7345'42'’ 3219 m, IND-R 4251-2; Represa del Neusa, ICN 2201; Sabana de Bogotá, Laguna de Herrera, 3000-3100 m, ICN 1232-3, 1494; Sabana de Bogotá, Tabio, 455'0' 'N, 745'60' O, 2630-2650 m, ICN 1230; San Cayetano, 453'11'’N, 7324'20' O, 2080 m, ICN 6758; Sasaima, 453'53' N, 74²6'13'’O, 2311 m, IND-R 276; Sibaté, 4²9'29' 'N, 74¹5'38'’O, 2730 m, IND-R 583-4; Tenjo, 452’27'’N, 748'54'’O, 2679 m, ICN 2415; Usaquén, 442'0' 'N, 74¹'60' 'O, 2727 m, ICN 1236-7; Vía a Choachi, ICN 6252; Zipaquirá, 5¹'42'’N, 74³'30' O, 2892 m, ICN 2818-9; Zipaquirá, Laguna Verde, 3670 m, ICN 6069-73; localidad no especificada, USNM 153972, 153987-91. No specific political unit: Páramo de Sumapas, cerca de Laguna Larga, 3800 m, ICN 2378. Localidad no especificada: SDSU 1692-5.

Stenocercus varius. ECUADOR: Provincia Cotopaxi: Reserva Integral de Bosque Nublado La Otonga, 044'0' 'S, 7859'0' O, 2000-2200 m, QCAZ 3118; Peñas Coloradas, QCAZ 1695; San Francisco de Las Pampas, 0²6'0' 'S, 7857'0' O, QCAZ 86-91,

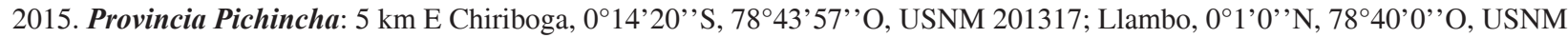
201318-20, 201322; Estación Forestal La Favorita, 0¹4'0',S, 7846'0'’O, 1900 m, FHGO 354, 412, 424, 445; Reserva Florística Ecológica Río Guajalito, 0`14'0' 'S, 7848'0'’O, 1840 m, QCAZ 717, 719, 1334, 3046, FHGO 337; Río Blanco, EPN 5932; Tandapi, $0^{\circ} 25^{\prime} 0^{\prime}$ 'S , 78 47'0' 'O, 1460 m, QCAZ 590-1, 593-6. No specific political unit: Las Máquinas, AMNH 27135. [Provincia Pastaza]: Mera, Río Pastaza (en error), AMNH 60602-4. Localidad no especificada: BMNH 71.4.16.53 (holotipo). 